\title{
Study the Double-Transfer Path of Guangdong Province on Gravity Model and Cluster Analysis
}

\author{
— Taking Foshan's Ceramics Industry as an Example \\ Yun Liang', Xiaode Zuo ${ }^{2}$ \\ ${ }^{1}$ Guangdong University of Finance, Guangzhou, China \\ ${ }^{2}$ Management School, Jinan University, Guangzhou, China \\ E-mail: tliangy5@163.com, tzuoxd@jnu.edu.cn \\ Received September 12, 2010; revised October 15, 2010; accepted October 18
}

\begin{abstract}
Gravity model and system cluster method are integrated in this paper to generate a regression analysis on the gravity of many transferees of Foshan's ceramics industry, which are discussed under the background of the industry and human resource transfer practice. Also the value and role orientation of the industries, enterprises and governments in the transfer process are explored, which provides theoretic guidance to the transfer practice. The analyzing results show us, the gravity of transferees in Guangdong province is bigger when compared to other areas.
\end{abstract}

Keywords: Industry Transfer, Gravity Model, Cluster Analysis, Regression Analysis

A large scale of enterprises has emerged since china's reform and opening up, which constitute to a certain industry structure. Along with the spread of financial crisis, the mode of export-oriented economy confronts great difficulties that never seen, putting the industry structure upgrading and transformation at the edge. The concept of "Double- transfer" was created in Guangdong Province of China, which contains industry transfer and labor transfer, means that the labor-intensive industry will transfer from Pearl River Delta to east, west and north Guangdong; while the labor of east, west and north Guangdong will transfer to local secondary and tertiary industry, some of qualified ones will transferred to Pearl River Delta area.

Transfer from advanced economies to developing ones is the basic path of industry transfer, with the aim of shortening regional economic gap and promoting harmonious development. Lots of factors can affect industry transfer, natural resource, labor, capital, technology, infrastructure, geographical location, cultural environment, policy environment, market environment and so on. The following questions come whether double-transfer will successfully carry out. What kinds of industries and labor should be transferred? Where should they be transferred?

This paper applies the gravity model and cluster analysis to industry transfer, tries to evaluate the influential factors to them, calculates every city's gravity through cluster analysis, whose outputs would be taken as the inputs to do the electrometrical analysis, through which all factor's parameters can be decided, providing theoretical guidance to the double- transfer practice.

\section{Descriptions to the Gravity Model}

The gravity model is based on the theory of Universal Gravitation Principal. It goes that, the gravity between two objects obeys to the function:

$$
F_{i j}=G \times \frac{M_{1} M_{2}}{D_{i j}^{2}}
$$

while $M_{i}, M_{j}$ means the mass of the two objects, $D_{i j}$ is the distance between them, and $G$ is the gravity constant.

Ever since 1960s, some scholars began to use gravity model to research bilateral trade volume [1,2]. Reference [3] used GDPs of two countries to replace the objects' mass, and the distance between two countries to that between the objects. The logarithm form was adopted to make the model linear. He analyzed bilateral trade data of 15 developed countries and 3 developing countries of year 1959 and found out that, the bilateral trade flow is greatly dependent on the economic scales of two countries and the geographical distance between them. Almost at the same time, German economist Poyhonen (1963) [4] studied bilateral trade with gravity model. 
Trading gravity model can be simply expressed as $T_{i j}=\beta\left(\frac{Y_{i} Y_{j}}{D_{i j}}\right)$ [5]. while $T_{i j}$ is the trade volume between two countries, $Y_{i}$ and $Y_{j}$ are GDPs of country $i$ and country $j, D_{i j}$ is the distance between the two countries, and $\beta$ is a constant. From the model, the bilateral trade volume is positively related to economic scales of the two countries and negatively related to the distance between them.

Gravity model improves itself along with its wide application. For example, Linnemann added population as a new explanatory variable to the model. While in 1970s, many variables such as virtual variables, non-tariff coverage index, bilateral exchange rate, income per capita, common language, population intensity and so on were introduced into the model. Although it is been doubted and criticized for lacking of theoretical foundation, it has won big success in practical use. [6-11]. However, gravity model is seldom seen to be used in studying industry transfer. Reference [12] conducted a research on the transfer of Electronic and communication equipment manufacturing industry between 2001 to 2003 .

System cluster is the most widely used cluster method. Its basic concept lies in, take each sample as a cluster, combine the closest ones according to the sample's similarity, and calculate the distances between the combined clusters, then combine them as above. Continue the process until all the samples become one cluster. Among them, the square of Euclidean distance is used to evaluate the similarity among clusters, and averaging method is used as cluster method.

\section{Model Descriptions}

\subsection{Set up the Model}

Every industry has its own characteristics and different influential factors. Here ceramic industry of Foshan city is chosen to illustrate the application of gravity model.

First the model brought by Tinbergen,

$X_{i j}=\alpha_{0} Y_{i}^{\alpha_{1}} Y_{j}^{\alpha_{2}} D_{i j}^{\alpha_{3}} P_{i j}^{\alpha_{4}}$, is written into the form of natural logarithm:

$$
\ln X_{i j}=\ln \alpha_{0}+\alpha_{1} \ln Y_{i}+\alpha_{2} \ln Y_{j}+\alpha_{3} \ln D_{i j}+\alpha_{4} \ln \mathrm{P}_{\mathrm{ij}}
$$

Some of the parameters are re-defined according to industry transfer practice.

1) $i=1,2 \ldots \ldots$, indicates the cities that an industry transfer from, $j=1,2 \ldots \ldots \mathrm{m}$, indicates the cities that an industry transfer to. $X_{i j}$ means the gravity between two cities.

2) $Y_{i}, Y_{j}$ demonstrate industry outputs of city $i$ and city $j$. The bigger the output is, the stronger the gravity to an industry.

3) $D_{i j}$ is the economic distance between the two cities, whose value is obtained from two time's weighting to their physical distance. The function of economic distance can be expressed as:

$$
D_{i j}=\alpha \times \beta \times D
$$

$D$ is the geographical distance, $\alpha$ is the geographic weight, Which decided by the transportation situations between two cities, $\beta$ is the economy weight decided by the ratio of GDP per capita of the transferee and transferor cities. Table 1 shows how the economic distance is calculated.

4) $P_{i j}$ is the transferring parameter between two cities, measured by two governments' beneficial policies to the certain industry. The gravity will be bigger if the governments offer some convenience. Here in the doubletransfer practice, $P_{i j}=1$ in Guangdong province, and 0 in other regions.

5) the labor volume is inneglectable, rich human resource is an important attractions to industry transfer, the permanent residence is used in this function.

6) special resource gift of transferee areas. The development of a certain industry relies on certain resources, such as land, energy and so on. Therefore, if the region possesses resource, it has a value of 1, 0 if it doesn't.

\begin{tabular}{|c|c|c|c|c|c|c|c|}
\hline \multicolumn{8}{|c|}{ Geographical distance weight $\alpha$} \\
\hline Transportation tool & train & van & ship & Train and van & Train and ship & Van and ship & Train, van and ship \\
\hline$\alpha$ & 1 & 1.2 & 1.5 & 0.7 & 0.8 & 1.1 & 0.5 \\
\hline \multicolumn{8}{|c|}{ Economic distance weight $\beta$} \\
\hline \multicolumn{4}{|c|}{$\begin{array}{l}\text { GDP per capita that industry transfers from/GDP per } \\
\text { capita that industry transfers to }\end{array}$} & \multicolumn{2}{|c|}{$>70 \%$} & $\% \geq$ ratio $\geq 45 \%$ & $<45 \%$ \\
\hline \multicolumn{4}{|c|}{$\beta$} & \multicolumn{2}{|c|}{0.8} & 1.0 & 1.2 \\
\hline
\end{tabular}

Table 1. Parameters of economic distance. 
Based on the above description, the new model can be written as

$$
\begin{aligned}
\ln F_{i j} & =\alpha_{0}+\alpha_{1} \ln Y_{j}+\alpha_{2} \ln D_{i j}+\alpha_{3} \ln l a b_{j} \\
& +\alpha_{4} P_{j}+\alpha_{5} \text { res }+\mu_{i j}
\end{aligned}
$$

We can conclude 5 factors that affect a city's gravity to an industry, they are industry output, economic distance, labor volume, beneficial policies and natural resource gift. The data of these 5 factors are used to cluster analysis to measure each city's gravity.

\section{Double Transfer of Foshan's Ceramics Industry}

14 cities are selected as potential areas that the industry will transfer to: Qingyuan, Zaoqing, Heyuan, Jiajiang, Jingdezhen, Gaoan, Fengcheng, Liling, Huanggang, Zibo, linyi, Faku, Jinjiang, and Yining.

First we calculate the economic distance between the above cities and Foshan, the results are shown in Table 2.

Other parameter's values are shown in Table $3^{1}$ :

SPSS16.0 is adopted to do the cluster analysis. Standardize all variables and make them easy to be compared.

The classfing results are shown as in Figure $\mathbf{1}$ and Figure 2:

Dendrogram using Average Linkage (Between Groups)

Figure 2 shows the situations when the 14 cities been classified to 2, 3, 4, 5 and 6 clusters. It is quite obvious that if been classified by gravity, from bottom to up, to 2 clusters, Faku and Yining are in one cluster and the other 12 cities in the other group; if been classified into 3 clusters, Yining in one cluster, Faku another, and the remaining cities the third. If 6, Yining the first cluster, then Faku, Linyi the third, Jingdezhen the forth, Huanggang, Jiajiang, Liling, Jinjiang, Gaoan, Fengcheng and Zibo the fifth, and Qingyuang, Zaoqing Heyuang the sixth cluster.

Only four factors' influences have been considered in the model. After cluster analysis, the industry transferring direction is quite clear and practical: the potential areas with biggest gravity are in group one, Qingyuang, Zaoqing and Heyuang. That is because of short economic distance and governments' great push on double-transfer policy. Jiajiang and Liling have sound transportation conditions and are rich in resources, some places such as Gaoan and Fengcheng have already formed the ceramics industry chain. While with a long distance from Foshan, weak transportation situation and low GDP level, Yining has little gravity to the ceramics industry even it possess many natural resources and has a great market coverage. It is noted that, although Jingdezhen is a famous city with de

${ }^{1}$ Data of GDP per capita and labor volume are from statistical yearbook of 2008 .
Table 2. Economic distance between Foshan and potential cities.

\begin{tabular}{cccccc}
\hline No. & $\begin{array}{c}\text { Potential } \\
\text { cities }\end{array}$ & $\mathrm{D}(\mathrm{km})$ & $\alpha$ & $\beta$ & Dij \\
\hline 1 & Qingyuan & 74.06 & Train, van 0.7 & 1.20 & 62.2104 \\
2 & Zaoqing & 70.35 & train, van 0.7 & 1.20 & 59.094 \\
3 & Heyuan & 185.73 & train, van 0.7 & 1.20 & 156.0132 \\
4 & Jiajiang & 1210.15 & train, van 0.7 & 1.20 & 1016.526 \\
5 & Jingdezhen & 804.7 & train, van 0.7 & 1.20 & 675.948 \\
6 & Gaoan & 641.97 & van 1.2 & 1.20 & 924.4368 \\
7 & Fengcheng & 629.71 & train, van 0.7 & 1.20 & 528.9564 \\
8 & Liling & 516.39 & train, van 0.7 & 1.20 & 433.7676 \\
9 & Huanggang & 845.96 & van 1.2 & 1.20 & 1218.182 \\
10 & Zibo & 1611.15 & train, van 0.7 & 0.80 & 902.244 \\
11 & Linyi & 1431.44 & train, van 0.7 & 1.20 & 1202.41 \\
12 & Faku & 2367.24 & van 1.2 & 1.20 & 3408.826 \\
13 & Jinjiang & 590.52 & Van, ship 1.1 & 1.00 & 649.572 \\
14 & Yining & 3714.63 & Van 1.2 & 1.20 & 5349.067 \\
\hline & & & & & \\
\hline
\end{tabular}

\begin{tabular}{|c|c|c|c|c|c|c|}
\hline No. & $\begin{array}{l}\text { Potential } \\
\text { cities }\end{array}$ & $\begin{array}{c}\mathrm{Y} \\
\text { (100 million } \\
\text { Yuan) }\end{array}$ & Dij (km) & $\begin{array}{c}\text { Lab } \\
\text { (1000 per) }\end{array}$ & Pij & Res \\
\hline 1 & Qingyuan & 21.86 & 62.2104 & 365.87 & 1.5 & 0 \\
\hline 2 & Zaoqing & 9.01 & 59.094 & 375.20 & 1.5 & 0 \\
\hline 3 & Heyuan & 6.14 & 156.0132 & 281.82 & 1.5 & 0 \\
\hline 4 & Jiajiang & 50.00 & 1016.526 & 35.00 & 1 & 0 \\
\hline 5 & Jingdezhen & 42.00 & 675.948 & 155.44 & 1 & 0 \\
\hline 6 & Gaoan & 12.46 & 924.4368 & 80.80 & 1 & 1 \\
\hline 7 & Fengcheng & 10.00 & 528.9564 & 133.30 & 1 & 0 \\
\hline 8 & Liling & 90.00 & 433.7676 & 98.39 & 1 & 0 \\
\hline 9 & Huanggang & 8.00 & 1218.182 & 666.70 & 1 & 0 \\
\hline 10 & Zibo & 18.00 & 902.244 & 419.59 & 1 & 0 \\
\hline 11 & Linyi & 17.00 & 1202.41 & 1027.50 & 1 & 0 \\
\hline 12 & Faku & 113.40 & 3408.826 & 45.00 & 1 & 1 \\
\hline 13 & Jinjiang & 70.00 & 649.572 & 158.70 & 1 & 0 \\
\hline 14 & Yining & 3.00 & 5349.067 & 44.22 & 1 & 1 \\
\hline
\end{tabular}

Table 3. Parameter's value of potential areas. 


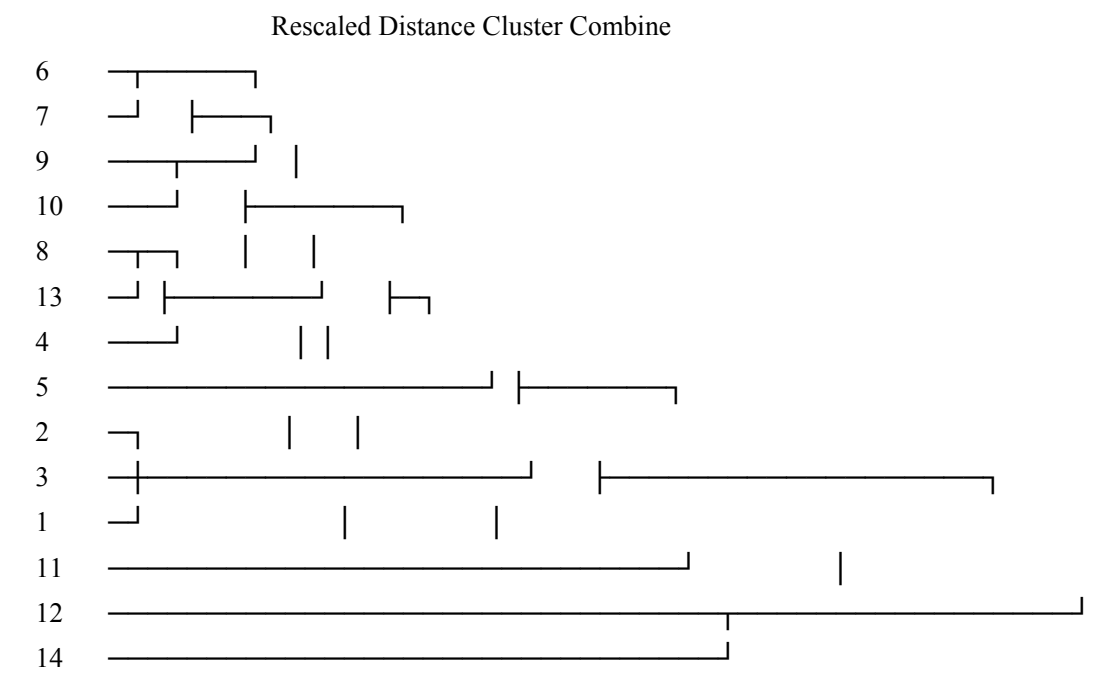

Figure 1. Cluster tree chart.

\begin{tabular}{|c|c|c|c|c|c|}
\hline \multicolumn{7}{|c|}{ Cluster Membership } \\
\hline Case & 6 Clusters & 5 Clusters & 4 Clusters & 3 Clusters & 2 Clusters \\
\hline 1 & 1 & 1 & 1 & 1 & 1 \\
\hline 2 & 1 & 1 & 1 & 1 & 1 \\
\hline 3 & 1 & 1 & 1 & 1 & 1 \\
\hline 4 & 2 & 2 & 1 & 1 & 1 \\
\hline 5 & 3 & 2 & 1 & 1 & 1 \\
\hline 6 & 2 & 2 & 1 & 1 & 1 \\
\hline 7 & 2 & 2 & 1 & 1 & 1 \\
\hline 8 & 2 & 2 & 1 & 1 & 1 \\
\hline 9 & 2 & 2 & 1 & 1 & 1 \\
\hline 10 & 2 & 2 & 1 & 1 & 1 \\
\hline 11 & 4 & 3 & 2 & 1 & 1 \\
\hline 12 & 5 & 4 & 3 & 2 & 2 \\
\hline 13 & 2 & 2 & 1 & 1 & 1 \\
\hline 14 & 6 & 5 & 4 & 3 & 2 \\
\hline
\end{tabular}

Figure 2. Cluster membership.

-veloped ceramics industry, it is catalyzed into the third group for resource, policies reasons.

Based on the result of cluster analysis, evaluate the gravity of different group in an up-down order as 6, 5, 4, 3,
2, 1. Then do an electrometrical analysis to the influential factors in Function 3. Regression based on Least Squares method is adopted and Eviews 5.0 is used. The regression results are shown in Table 4.

From the table, $\mathrm{R}^{2}=0.914419$, the adjusted $\mathrm{R}^{2}=$ 0.860930 , which tells that the variables we chose can explain more than $86 \%$ of the gravity. $\mathrm{F}=17.09564$, which is bigger than critical value 2.73 . to every single variable, it is found that t-Statistic is not significant, such as Res. That probably because ceramics industry doesn't rely on resources very much. So the variable Res is kicked out, and regression is done again as shown in Table 5 :

$\mathrm{R}^{2}$ of this time is 0.914054 , and the adjusted one is 0.875856 , the value of $F$ is 23.91928 , bigger than F's value last time, which means the explaintory variables has a better explantation to the explained variable. a new function can be obtained based on function 3 :

$$
\begin{aligned}
\ln F j & =6.026752-0.007076 \ln Y_{j}-0.00917 \ln D_{i j} \\
& -0.001140 \ln l a b_{j}+0.534150 P j
\end{aligned}
$$

Here are the explanations: 1) the ceramics industry output is negatively related to the gravity, which is quite reasonable since a big output means a full covered market, providing great barrier to new entrants; 2) economic distance's effect is negative, but the parameter's value is small. It's easy to understand since with the improvements of transportation and economy, economic distance has little effect on ceramics industry, especially this industry doesn't need much physical transfer, most of the cases are building factories and purchasing equipments in the places that will transfer to. What transfer in the process are just technologies, capital and expertise. Also, economic gap is just a comparative concept which can 
Table 4. Regression analysis of ceramics industry.

\begin{tabular}{|c|c|c|c|c|}
\hline \multicolumn{5}{|c|}{ Dependent Variable: F } \\
\hline \multicolumn{5}{|c|}{ Method: Least Squares } \\
\hline \multicolumn{5}{|c|}{ Date: 07/04/09 Time: 01:34 } \\
\hline \multicolumn{5}{|l|}{ Sample: 114} \\
\hline \multicolumn{5}{|c|}{ Included observations: 14} \\
\hline Variable & Coefficient & Std. Error & t-Statistic & Prob. \\
\hline $\mathrm{C}$ & 6.036283 & 0.423007 & 14.26993 & 0.0000 \\
\hline $\mathrm{Y}$ & -0.007120 & 0.005169 & -1.377319 & 0.2057 \\
\hline DIJ & -0.000893 & 0.000176 & -5.080806 & 0.0010 \\
\hline LAB & -0.001187 & 0.000668 & -1.777148 & 0.1134 \\
\hline $\mathrm{P}$ & 0.538737 & 0.424937 & 1.267804 & 0.2405 \\
\hline RES & -0.113089 & 0.612503 & -0.184635 & 0.8581 \\
\hline R-squared & 0.914419 & \multicolumn{2}{|c|}{ Mean dependent var } & 4.500000 \\
\hline Adjusted R-squared & 0.860930 & \multicolumn{2}{|c|}{ S.D. dependent var } & 1.506397 \\
\hline S.E. of regression & 0.561767 & \multicolumn{2}{|c|}{ Akaike info criterion } & 1.982066 \\
\hline Sum squared resid & 2.524653 & \multicolumn{2}{|c|}{ Schwarz criterion } & 2.255948 \\
\hline Log likelihood & -7.874465 & \multicolumn{2}{|c|}{ F-statistic } & 17.09564 \\
\hline Durbin-Watson stat & 2.171311 & \multicolumn{2}{|c|}{$\operatorname{Prob}(F$-statistic) } & 0.000435 \\
\hline
\end{tabular}

Table 5. Regression results without Res.

\begin{tabular}{|c|c|c|c|c|}
\hline \multicolumn{5}{|c|}{ Dependent Variable: $\mathrm{F}$} \\
\hline \multicolumn{5}{|l|}{ Method: Least Squares } \\
\hline \multicolumn{5}{|c|}{ Date: 07/04/09 Time: $14: 39$} \\
\hline \multicolumn{5}{|l|}{ Sample: 114} \\
\hline \multicolumn{5}{|c|}{ Included observations: 14} \\
\hline Variable & Coefficient & Std. Error & t-Statistic & Prob. \\
\hline $\mathrm{C}$ & 6.026752 & 0.396677 & 15.19312 & 0.0000 \\
\hline $\mathrm{Y}$ & -0.007076 & 0.004879 & -1.450367 & 0.1809 \\
\hline DIJ & -0.000917 & 0.000114 & -8.057946 & 0.0000 \\
\hline LAB & -0.001140 & 0.000585 & -1.950037 & 0.0830 \\
\hline$P$ & 0.534150 & 0.400801 & 1.332708 & 0.2154 \\
\hline R-squared & 0.914054 & \multicolumn{2}{|c|}{ Mean dependent var } & 4.500000 \\
\hline Adjusted R-squared & 0.875856 & \multicolumn{2}{|c|}{ S.D. dependent var } & 1.506397 \\
\hline S.E. of regression & 0.530766 & \multicolumn{2}{|c|}{ Akaike info criterion } & 1.843461 \\
\hline Sum squared resid & 2.535412 & \multicolumn{2}{|c|}{ Schwarz criterion } & 2.071696 \\
\hline Log likelihood & -7.904230 & \multicolumn{2}{|c|}{ F-statistic } & 23.92918 \\
\hline Durbin-Watson stat & 2.082530 & \multicolumn{2}{|c|}{ Prob(F-statistic) } & 0.000082 \\
\hline
\end{tabular}


make up by beneficial policies and low costs; 3) Human resource, replaced by permanent residence, also has a negative but small effect on the gravity, which is quite understandable since ceramics industry doesn't need large number of qualified labor, making every city's human resources are sufficient for this industry; 4) government policy plays an important role here with a coefficient of 0.538737 . industry transfer has great influence on both regions that transfers from and transfers to, which deeply relied on goverments' policies. From this, the importance of Guangdong's double-transfer to promote industry transfer is quite obvious.

\section{Conclusions}

The influential factors are decided through gravity model, which are taken as the input to cluster analysis, whose results are given different group values as the value of different gravity levels. Then Eviews 5.0 is used to do the regression analysis. The following conclusions are drawn: 1) governments' beneficial policies play important roles in industry transfer process, that's why recipient governments enacted all kinds of polices to attract industries transferring in; 2) as to economic distance, its role in industry transfer is reduced since great improvement of transportation and economy conditions national wide; 3) Only five variables are considered in the model and cluster analysis, which maybe cannot explain the real situation sufficiently. Some variables are just hard to be quantified but still have huge influences on industry transfer; 4) also just the ceramics industry of Foshan has been studied in this paper, which is a small fraction of Guangdong's industry transfer business, more industries' practice can be research further. Moreover, some of data used in this paper are not so precise because of hard access.

\section{References}

[1] Anderson and E. A. James, "Theoretical Foundation for the Gravity Equation," The American Economic Review, Vol. 69, No. 1, 1979, pp. 106-116.

[2] D. J. Peng. "Ethnic Chinese Business Network and the Asia Pacific Economic Integration," Journal of Asian\& African Studies, Vol. 35, No. 2, 2000, pp. 229-250.

[3] J. Tinbergen, "Shaping the World Economy: An Analysis of World Trade Flows," New York Twentieth Century Fund, Vol. 5, No. 1, 1962, pp. 27-30.

[4] P. Poyhonen, "A Tentative Model of the Volume of Trade between Countries," The American Economic Review, Vol. 2, 1963, pp. 93-99.

[5] S. Bin and M. Z. Liao, "Trade Volume and Export Potential of China," World Economy, Vol. 2, 2004, pp. 3-12.

[6] J. H. Zhang, "Study on Investing Country Characteristics and Investment Intensity to China," World Economy, Vol. 1, 2004, pp. 16-22.

[7] X. Ruan and J. H. Zhao, "FDI Location Selection from the View of Gravity Model," world Economy, Vol. 2, 2004, pp. 67-71.

[8] C. C. Zhang, "Analysis on Investment Environment Factors That Affect FDI," Management World, Vol. 2, 2002, pp. 32-41.

[9] K. J. Gu, "International Economics' Development and Application on the Gravity Model," World Economy, Vol. 2, 2001, pp. 14-25.

[10] H. X. Shi and S. F. Liu, "Study on the transfer of electronic and communication equipment industry based on gravity model," Industry Technology Economics, Vol. 8, 2008.

[11] W. Sun, "Cluster Analysis on Equipment Manufacturing Industry in 29 Provinces of China," China Technology Forum, Vol. 6, 2005.

[12] D. R. Cheng and J. Li, "Study on the Interactivity of City Economics under Mulnucipal Economic Cycles Construction," Technology and Economics, Vol. 2, 2007, pp. 42-44. 